\title{
Association of Apgar score at five minutes with long-term neurologic disability and cognitive function in a prevalence study of Danish conscripts
}

\author{
Vera Ehrenstein*1,2, Lars Pedersen1, Miriam Grijota1 , Gunnar Lauge Nielsen ${ }^{1}$, \\ Kenneth J Rothman ${ }^{2,3}$ and Henrik Toft Sørensen ${ }^{1,2}$
}

Address: ${ }^{1}$ Department of Clinical Epidemiology, Aarhus University Hospital, Science Centre Skejby, Olof Palmes Allé 43-45, 8200 Aarhus N, Denmark, ${ }^{2}$ Department of Epidemiology, Boston University School of Public Health, 715 Albany Street, Boston, MA 02118, USA and ${ }^{3}$ RTI Health Solutions, Research Triangle Park, NC 27709, USA

Email: Vera Ehrenstein* - ve@dce.au.dk; Lars Pedersen - lap@dce.au.dk; Miriam Grijota - miriam.grijota@dce.au.dk; Gunnar Lauge Nielsen - guln@rn.dk; Kenneth J Rothman - krothman@bu.edu; Henrik Toft Sørensen - hts@dce.au.dk

* Corresponding author

Published: 2 April 2009

BMC Pregnancy and Childbirth 2009, 9:14 doi:10.1 |86/147|-2393-9-14

This article is available from: http://www.biomedcentral.com/I47/-2393/9//4

(c) 2009 Ehrenstein et al; licensee BioMed Central Ltd.

This is an Open Access article distributed under the terms of the Creative Commons Attribution License (http://creativecommons.org/licenses/by/2.0), which permits unrestricted use, distribution, and reproduction in any medium, provided the original work is properly cited.
Received: 27 August 2008

Accepted: 2 April 2009

\begin{abstract}
Background: Apgar score is used for rapid assessment of newborns. Low five-minute Apgar score has been associated with increased risk of severe neurologic outcome, but data on milder outcomes, particularly in the long term, are limited. We aimed to examine the association of fiveminute Apgar score with prevalence of neurologic disability and with cognitive function in early adulthood.

Methods: We conducted a prevalence study among draft-liable men born in Denmark in 19781983 and presenting for the mandatory army evaluation in a northern Danish conscription district. We linked records of this evaluation, which includes medical exam and intelligence testing, with the conscripts' records in the Medical Birth Registry, containing perinatal data. We examined prevalence of neurologic disability and of low cognitive function according to five-minute Apgar score.

Results: Less than I\% (I36/19,559) of the conscripts had 5-minute Apgar scores $<7$. Prevalence of neurologic disability was $2.2 \%$ (435/19,559) overall; among conscripts with Apgar scores $<7,7-$ 9 , and 10 (reference), it was $8.8 \%, 2.5 \%$, and $2.2 \%$ respectively. The corresponding prevalences of low cognitive function (intelligence test score in the bottom quartile) were $34.9 \%, 27.2 \%$, and $25.0 \%$. The outcomes were more prevalent if Apgar score $<7$ was accompanied by certain fetal or obstetric adversities. After accounting for perinatal characteristics, 5-mintue Apgar score $<7$ was associated with prevalence ratios of 4.02 (95\% confidence interval: $2.24 ; 7.24)$ for neurologic disability and $1.33(0.94 ; 1.88)$ for low cognitive function.
\end{abstract}

Conclusion: A five-minute Apgar score $<7$ has a consistent association with prevalence of neurologic disability and with low cognitive function in early adulthood. 


\section{Background}

Apgar score [1], used to evaluate infant's condition immediately after birth, is a sum of ratings $(0,1$, or 2$)$ of five clinical signs: heart rate, respiration, reflex irritability, muscle tone, and color. Five-minute Apgar scores below 4 are strong predictors of neonatal mortality [2]. Antenatal $[3,4]$ and peripartum [5] adversities associated with fiveminute Apgar scores below 7 [6-8] have been implicated in neonatal brain injury, which in turn may lead to neurodevelopmental disability [9-13].

Most newborns with Apgar scores below 7 grow up healthy, but risks of neurodevelopmental disability among them are greater than among those with higher Apgar scores, particularly in the short term [8,14-16]. Increased risks have been reported for neonatal seizures [8]; neonatal intracranial hemorrhage [8]; cerebral palsy $[8,14,15]$; mental retardation [8]; and epilepsy $[16,17]$. There are also reports of association between five-minute Apgar scores below 7 and risk of motor and developmental impairments at school age, including symptoms of attention deficit [18] and speech and language problems [19]. Less is known about long-term or mild neurodevelopmental disability among newborns with low Apgar scores. Recently, Odd et al., in a large study of Swedish conscripts, reported that worse cognitive performance was related to taking a longer time to achieve an Apgar score $>6$ [20]. This finding was in contrast to an earlier study by Seidman et al., who found little association between Apgar score and cognitive function among Israeli draftees [21]. Neither of the studies examined outcomes in men who are exempt from the draft. We studied the association of five-minute Apgar score with neurodevelopmental outcomes among Danish draftees. In addition to cognitive function, we examined prevalence of neurologic diseases, some of which are grounds for exemption from the military service.

\section{Methods}

\section{Study population}

We conducted a prevalence study among Danish men who were born as singletons in 1978-1983 and presented for conscription in 1996-2002. Nearly all men in Denmark are draft-liable and must register with authorities in one of the country's conscription districts. We studied men registered in the fifth conscription district, with jurisdiction primarily over the northern Danish counties of North Jutland and Viborg. During the registration, men report diseases that potentially preclude military service. Draft board physicians verify such reports with health care providers, and men with a verified condition receive exemption from the military duty. Among the remaining men, suitability for the service is determined in a routine evaluation, which includes a medical examination and intelligence testing [22]. Based on this evaluation, additional men may be deemed 'unfit' for the army. All disa- bilities reported to the draft board are recorded in the conscripts' files using Danish version of International Classification of Diseases Tenth Revision (ICD-10) [23]. We linked the conscription records with the corresponding records in the Danish Medical Birth Registry. The unambiguous individual-level linkage is enabled by a unique identifier that has been assigned to all Danes at birth since 1968 and has since been used in all administrative and health databases [24].

Our study population comprised men surviving to conscription age. Conscription districts are determined by place of residence at age 18 years, which may differ from place of birth. Thus, the exact birth cohort of boys destined for a given conscription district was unknown, and our study population is best thought of as a prevalence population rather than a cohort.

\section{Perinatal characteristics}

The Danish Medical Birth Registry electronically tracks all births in Denmark since 1973 [25]. The data are entered from birth certificates filled out by midwives, who attend all births. From the Birth Registry, we extracted variables reportable at the time of the conscripts' birth: five-minute Apgar score, maternal age at delivery, marital status, parity; and newborn's birth weight, gestational age, total number of malformations, fetal presentation, and mode of delivery.

\section{Outcomes at conscription}

We examined prevalent outcomes recorded at the time of conscription. We defined 'neurologic disability' as a record of a 'disease of the nervous system' in the conscription file (ICD-10 diagnoses G [23]). We defined 'disqualifying neurologic disability' as having one of the above diagnoses combined with being deemed 'unfit' for the military. Cognitive function was measured by the Boerge Prien test (Danish Børge Prien Prøve, BPP), which has been used for conscription purposes since 1957. It is a 78item group intelligence test with four subscales (letter matrices, verbal analogies, number sequences, and geometric figures) and a single final score, recorded as the number of correctly answered items (range 0-78) [26]. BPP scores are strongly correlated with conventional intelligence-test scores (e.g., correlation of 0.82 with the Wechsler Adult Intelligence Scale [27]). For comparison with other studies, we converted Boerge Prien scores to the more conventional intelligence quotient (IQ) scale ( mean $=100$, standard deviation $=15[28]$ ) and examined distributions of the converted BPP scores and prevalence of low cognitive function, which we defined as a score in the bottom quartile.

\section{Data analysis}

We examined all study outcomes according to five-minute Apgar score in categories $<7,7-9$, and 10 (reference) [16]. 
We repeated these analyses in groups of maternal age at delivery $(\leq 20,21-35,>35$ years); maternal marital status (married/unmarried); parity $(0, \geq 1)$; breech presentation; mode of delivery (vaginal, Cesarean, instrument); gestational age ( $<37,37-41, \geq 42$ weeks) and birth weight small for gestational age (SGA), defined as weight $<10^{\text {th }}$ percentile of all male live births in a given gestational week. We examined whether any association of Apgar score with the study outcomes could be explained by characteristics that are risk factors for both low Apgar score and for neurodevelopmental disability [9-13]. We used Zou's method of modified Poisson regression with robust error variance [29] to estimate prevalence ratios for neurologic disability and for low cognitive function; we used linear regression to estimate mean differences in IQ scores. Gestational age was missing for $17 \%$ of the conscripts owing to incomplete reporting in the earlier years of birth registration. To avoid loss of observations, we filled in missing values for gestational age using multiple imputation. The regression model used for imputation included variables for maternal age, marital status, parity, mode of delivery, conscript's birth year, birth presentation, birth weight, Apgar score at 1 minute, Apgar score at 5 minutes, neurologic disability, BPP score, and hearing and visual function measured at conscription [30]. Using a two-stage imputation procedure [31], we created five imputed datasets and averaged the estimates of effect for each outcome across the five datasets. The confidence intervals around these estimates reflect random error from the observed data and the uncertainty from the imputed values. We used SAS software, version 9.1 (SAS Inc., Cary, NC).

The study was approved by the Danish Registry Board. An informed consent was not required for this study of routine records.

\section{Results \\ Descriptive data}

Of the 19,843 draft-liable men born in 1978-1983 and registered with the fifth conscription district, 284 (1.4\%) had missing data on five-minute Apgar score and were excluded. Of the remaining 19,559 men, 2336 (12\%) men received health-related exemption before the formal evaluation, and therefore they did not undergo intelligence testing. The median age at the evaluation was 19 years (quartiles, 19-20 years). A large majority (93.4\%) of the men had Apgar score of 10 at 5 minutes of age; $136(0.7 \%)$ had Apgar score below 7 , and $1143(5.9 \%)$, a score in the range from 7 to 9 . Fiveminute Apgar score was inversely associated with prevalence of maternal nulliparity and unmarried status; and with prevalence of preterm birth, low birth weight, and Cesarean or instrument delivery (table 1).

\section{Neurologic disability}

A neurologic disability as defined here was reported at conscription for 435/19,559 (2.2\%) of the men (table 2).
The prevalence of neurologic disability among men with a five-minute Apgar score $<7$ was $8.8 \%$ (12/136), and it was $2.5 \%$ (29/1143) among men with five-minute Apgar scores in the 7-9 range. A disqualifying neurologic disability was recorded among 273 (1.4\%) of the conscripts, with epilepsy (ICD-10 codes G40.x) and cerebral palsy (ICD-10 codes G80.x-G83.x) accounting for $60 \%$ of the diagnoses. Among the 168 conscripts with neurologic disability who were not considered unfit, the most frequent diagnosis was migraine (73\%). Among the 435 men with a neurologic disability, the proportion of disqualified men was inversely related to the Apgar score: 11/12 (92\%; 95\% CI: 61\% - 100\%); 20/29 (68\%; 95\% CI: 49\% $85 \%$ ), and 242/394 (61\%; 95\% CI: 56\% - 66\%) in fiveminute Apgar scores categories <7, 7-9, and 10, respectively.

\section{Cognitive function}

Among the 17,223 men who underwent the intelligence testing, we excluded eight records with a missing score and additional four records with BPP scores below 10, all of which we considered data entry errors. Among the remaining 17,211 men, IQ scores were normally distributed, and the distributions did not differ substantially according the Apgar score categories (figure 1). Compared with those whose five-minute Apgar score was 10, mean differences in IQ scores were -2.6 points (95\% CI, -5.4 ; $0.3)$ and -1.0 points $(95 \% \mathrm{CI},-1.9 ; 0.0)$ for men with 5 mintue Apgar scores $<7$ and 7-9, respectively. Prevalence of low cognitive function among those with a five-minute Apgar score $<7$ was $34.9 \%$, which was greater than the $25 \%$ expected given our definition of low cognitive function as a score in the bottom quartile (table 2). The observed prevalence of low cognitive function differed from the expected value of $25 \%$ among conscripts who were born to mothers aged 20 years or younger $(36.3 \%)$ or those who were SGA $(32.9 \%)$. Greater differences from the expected distribution were seen among those who had five-minute Apgar score $<7$ coupled with maternal age 20 years or younger $(60.0 \%)$; with preterm birth $(40.9 \%)$; with SGA (50.0\%); or with instrument delivery (48.1\%). These estimates are based on small number of 'events'.

\section{Regression modeling}

Additional file 1 shows results of regression modeling. Inclusion in the model of the measured maternal and fetal characteristics caused only slight attenuation in the crude prevalence ratios for Apgar scores $<7$ and $7-9$. We excluded the variable for mode of delivery from the final model, as it had no effect on the estimates. After controlling for other covariates, five-minute Apgar score $<7$ was associated with a four-fold increase in the prevalence of neurologic disability (prevalence ratio $=4.02(95 \% \mathrm{CI}$, $2.24 ; 7.24)$ ), and with nearly a six-fold increase in prevalence of disqualifying neurologic disability (prevalence 
Table I: Perinatal characteristics of the 19559 conscripts according to five-minute Apgar score

\begin{tabular}{|c|c|c|c|c|}
\hline & \multicolumn{3}{|c|}{ Five-minute Apgar score } & \multirow[b]{2}{*}{ Total } \\
\hline & $<7$ & 7-9 & 10 & \\
\hline Number & $136(0.7 \%)$ & I I 43 (5.8\%) & 18280 (93.5\%) & 19559 (100.0\%) \\
\hline \multicolumn{5}{|l|}{ Mother's marital status } \\
\hline Married & $78(57.4 \%)$ & 727 (63.6\%) & $12332(67.5 \%)$ & 13 I 37 (67.2\%) \\
\hline Unmarried & $58(42.6 \%)$ & $416(36.4 \%)$ & $5948(32.5 \%)$ & $6422(32.8 \%)$ \\
\hline \multicolumn{5}{|l|}{ Parity } \\
\hline 0 & $82(60.3 \%)$ & $570(49.9 \%)$ & 7789 (42.6\%) & $844 \mid(43.1 \%)$ \\
\hline 1 & $29(21.3 \%)$ & $375(32.8 \%)$ & $6999(38.3 \%)$ & 7403 (37.9\%) \\
\hline$\geq 2$ & $25(18.4 \%)$ & $198(17.3 \%)$ & $3492(19.1 \%)$ & $3715(19.0 \%)$ \\
\hline \multicolumn{5}{|l|}{ Mother's age, years } \\
\hline$\leq 20$ years & $14(10.3 \%)$ & $119(10.4 \%)$ & $1724(9.4 \%)$ & 1857 (9.5\%) \\
\hline $21-35$ years & 113 (83. I\%) & $956(85.1 \%)$ & 15529 (85.9\%) & $16598(86.5 \%)$ \\
\hline$>35$ & $9(6.6 \%)$ & $68(5.9 \%)$ & $1027(5.6 \%)$ & $1104(5.6 \%)$ \\
\hline \multicolumn{5}{|l|}{ Gestational age, weeks } \\
\hline$<37$ & $28(20.6 \%)$ & $132(11.6 \%)$ & $543(3.0 \%)$ & $703(3.6 \%)$ \\
\hline $37-42$ & $74(54.4 \%)$ & $739(64.6 \%)$ & 13260 (72.5\%) & 14073 (71.9\%) \\
\hline$\geq 42$ & $14(10.3 \%)$ & $107(9.4 \%)$ & $1338(7.3 \%)$ & $1459(7.5 \%)$ \\
\hline Missing & $20(14.7 \%)$ & 165 (14.4\%) & $3139(17.2 \%)$ & $3324(17.0 \%)$ \\
\hline \multicolumn{5}{|l|}{ Birth weight, gram } \\
\hline$<2500$ & $4 \mathrm{I}(30.2 \%)$ & $128(11.2 \%)$ & $553(3.0 \%)$ & 722 (3.7\%) \\
\hline$\geq 2500$ & $95(69.8 \%)$ & $1002(87.6 \%)$ & 17598 (96.3\%) & 18695 (95.6\%) \\
\hline Missing & $0(0.0 \%)$ & $13(1.1 \%)$ & $129(0.7 \%)$ & $142(0.7 \%)$ \\
\hline SGA & $18(13.2 \%)$ & $117(10.2 \%)$ & 1473 (8.1\%) & $1608(8.2 \%)$ \\
\hline \multicolumn{5}{|l|}{ Mode of delivery } \\
\hline Vaginal unassisted & $69(50.7 \%)$ & 681 (59.6\%) & 14895 (81.5\%) & 15645 (80.0\%) \\
\hline Cesarean delivery & $34(25.0 \%)$ & $234(20.5 \%)$ & 1728 (9.4\%) & 1996 (10.2\%) \\
\hline Instrument delivery & $33(24.2 \%)$ & $228(19.9 \%)$ & $1657(9.1 \%)$ & $1918(9.8 \%)$ \\
\hline \multicolumn{5}{|l|}{ Fetal presentation } \\
\hline Cephalic & III (8I.6\%) & 1026 (89.8\%) & 17183 (94\%) & $18320(93.7 \%)$ \\
\hline Breech & $23(16.9 \%)$ & $105(9.2 \%)$ & 903 (4.9\%) & $1031(5.3 \%)$ \\
\hline Missing & $2(1.5 \%)$ & $12(1.0 \%)$ & $194(1.1 \%)$ & $208(1.1 \%)$ \\
\hline
\end{tabular}

Table 2: Neurologic disability and low cognitive function according to five-minute Apgar score.

\begin{tabular}{|c|c|c|c|c|c|}
\hline \multirow{3}{*}{$\begin{array}{c}\text { Five-minute Apgar } \\
\text { score }\end{array}$} & \multicolumn{3}{|c|}{ All conscripts } & \multirow{2}{*}{\multicolumn{2}{|c|}{$\frac{\text { Conscripts with measured cognitive function }}{\text { Low cognitive functionc }}$}} \\
\hline & \multirow[b]{2}{*}{$\mathbf{N}$} & \multirow{2}{*}{$\frac{\text { Neurologic disabilitya }^{\mathbf{a}}}{\mathrm{n}(\%)}$} & \multirow{2}{*}{$\begin{array}{r}\begin{array}{c}\text { Disqualifying neuro- } \\
\text { logic disability }\end{array} \\
\text { n (\%) }\end{array}$} & & \\
\hline & & & & $\mathbf{N}$ & n (\%) \\
\hline$<7$ & 136 & $12(8.8)$ & II (8.I) & 106 & $37(34.9)$ \\
\hline $7-9$ & 1143 & $29(2.5)$ & $20(1.8)$ & 992 & $244(27.2)$ \\
\hline 10 & 18280 & $394(2.2)$ & $242(1.3)$ & 16113 & $3562(25.0)$ \\
\hline Overall & 19559 & $435(2.2)$ & $273(1.4)$ & 17211 & $4344(25.2)$ \\
\hline
\end{tabular}

a Defined as a record of a diagnosis G ('diseases of nervous system' in ICD-I0), noted in conscripts' draft board record.

b Twenty-one men had no entry for army fitness.

c Defined as an IQ in the bottom quartile

ratio $=5.94(95 \% \mathrm{CI}, 3.19 ; 11.06))$. We saw a similar pattern for low cognitive function, but this measure is expected to be weaker because the prevalence in the reference group is by definition around $25 \%$, limiting the maximum ratio to 4 . For this measure we found a prevalence ratio of 1.33 (95\% CI, $0.94 ; 1.88$ ) after controlling for the covariates. The mean difference in conventional IQ score was $-1.8(95 \% \mathrm{CI},-4.7 ; 1.0)$ and -0.9 (95\% CI, $-1.9 ; 0.0)$, for five-minute Apgar score $<7$ and $7-9$, respectively, compared with Apgar score of 10, after controlling for covariates. Similar estimates were obtained in complete-subject analyses (done without imputation) or after excluding 


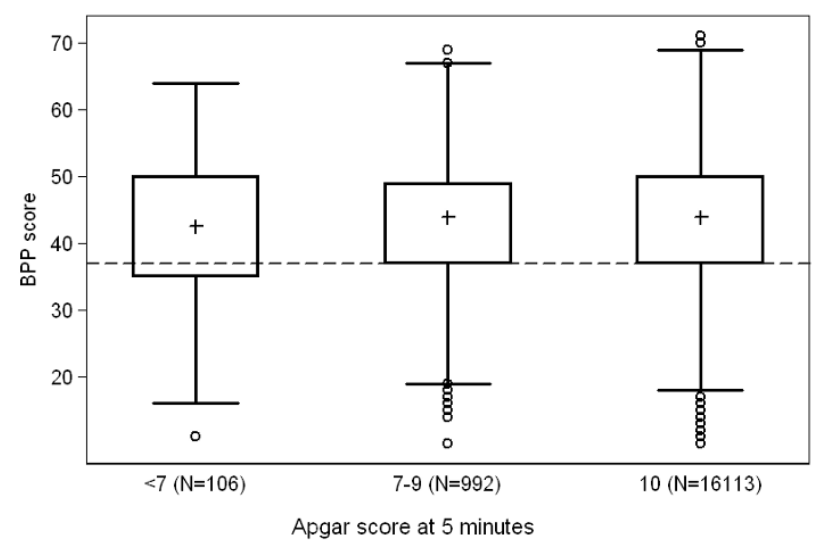

Figure I

Box-and-whisker plots of Boerge Prien test scores converted to the conventional IQ scale (mean $=100$, standard deviation $=$ I 5) according to Apgar score at 5 minutes. Pluses indicate median values; dashed line marks the bottom quartile of the overall distribution.

men with a record of a malformation in the Birth Registry $(\mathrm{N}=292$, data not shown).

\section{Discussion}

Having an Apgar score below 7 at five minutes was associated with greater prevalence of neurologic disability and of low cognitive function among Danish draftees. An Apgar score $<7$ may be a marker for severity of neurologic impairment, as suggested by its inverse association with proportion of disqualifying neurologic diagnoses. The absolute risk increases of $6.6 \%$ for neurologic disability and $9.9 \%$ for low cognitive function associated with five-minute Apgar score $<7$ imply a low sensitivity and thus a limited clinical utility in predicting long-term disability. At the same time, we found limited evidence of the absolute increase in risk of low cognitive function rising to $15 \%-35 \%$ if Apgar score $<7$ was accompanied by very young maternal age, growth restriction, or instrument delivery. Accounting for measured perinatal characteristics attenuated but did not fully account for the observed associations. The results indicate that low Apgar score is associated with impaired neurodevelopment through several mechanisms, only some of which involve clinical characteristics typically observed at birth. Five-minute Apgar scores in the 7-9 range were also associated with worse outcomes in our data, which is consistent with the notion of gradual increase in risk with worsening of condition at birth.

Our findings regarding Apgar score and neurologic disability are in agreement with recent reports of an inverse association between five-minute Apgar score and longterm risk of epilepsy $[16,17]$. Unlike those studies, which ascertained epilepsy from computerized hospitalization records, we used diagnoses reported directly to physicians, which should be less likely to include false-positive diagnoses [32]. Our findings regarding cognitive function corroborate and extend existing knowledge. Odd et al., in a population of $>130,000$ Swedish draftees born in early 1970 s, found a small reduction in mean IQ scores associated with low Apgar scores, similar in magnitude to our findings. The estimate of risk ratio for poor cognitive function in our study, $1.33(0.94-1.88)$, and that from the study of Odd et al., 1.35 (95\% CI: 1.07-1.69) [20] were similar despite the latter study defining poor cognitive score as the bottom $9 \%$ of the distribution. In clinical practice, cutoffs of $<1$ and $<2$ standard deviations below the mean IQ are commonly used. In our data, prevalence ratios for those two definitions of low cognitive function associated with Apgar score $<7$ were, respectively, 1.44 (95\% CI: 1.00-2.07) and 1.74 (95\% CI: 0.80-3.81). These outcomes were not used in the main analyses because of small number of 'events' in the Apgar $<7$ group. Lawlor et al. found a 5-minute Apgar score $<8$ to be associated with a 1.6-point mean decrease in IQ among adolescents at age 14 years [33], a value similar to our estimate of a 1.8-point mean decrease. Seidman et al. found a nearly null association among Israeli conscripts [21] based on the examination of mean differences. We do not interpret a mean IQ decrease on the order of onetenth of one standard deviation as being clinically significant. On the other hand, a small population shift could reflect a more important deficit for subgroups of a population. By analogy, small shifts in the mean blood pressure of a population may be important for specific subgroups [34]. Thus, examining only mean difference may mask effects seen only in the fringes of the total distribution.

We estimated potential loss to follow-up from the underlying birth cohort in a sample of 14,288 boys born in the study area in 1980-1983. Before reaching conscription age, the emigration out of Denmark was $<1 \%$; and mortality was $1.2 \%$. For boys with five-minute Apgar scores below 7 , mortality before age 1 year was $28 \%$, most of the deaths occurring among boys with scores below four. The overall mortality before age 1 year was $0.8 \%$, which is consistent with the period nationwide estimates [35]. We had no information on potentially eligible men who may have been institutionalized for legal or health reasons. Thus, at conscription age, men with a history of low Apgar score appearing before the draft board represent a comparatively healthy subset of all newborns with low Apgar scores. As noted by Odd et al., the differential survival underscores the fact that associations between neonatal condition and adult neurodevelopment seem to persist even in relatively healthy men [20].

Misclassification of the newborn condition by recorded Apgar score could result from random data entry errors and from the partially subjective nature of the Apgar score. 
These errors can be assumed to be independent of the outcomes we examined and therefore unlikely to cause upward bias in our measures of association. Neurologic diagnoses among conscripts may be under-ascertained by the draft-file information, if only the first-reported disqualifying diagnosis is recorded. Nevertheless, the prevalence of neurologic conditions in our sample $(2.2 \%)$ is comparable with published population figures [36]. Accounting for measured perinatal characteristics caused prevalence ratios to decrease, implying that using bettermeasured or additional factors theoretically could reduce the observed associations. For example, accounting for socioeconomic markers other than maternal characteristics could explain part of the associations with cognitive function, as it did the Swedish cohort [20].

\section{Conclusion}

In conclusion, we found that certain indicators of adult neurologic function and its severity are present at birth and are indirectly measurable even with a crude index such as the Apgar score.

\section{Competing interests}

The authors declare that they have no competing interests.

\section{Authors' contributions}

VE, HTS, GLN, and KJR all substantially contributed to study conception, design and interpretation of data. VE drafted the article and analyzed the data. LP, MG, and GLN participated in dataset creation and data analysis. All authors revised the paper critically and gave their approval of the final version. VE is the guarantor.

\section{Additional material}

\section{Additional file 1}

Table. Association of five-minute Apgar score with neurologic disability and cognitive function.

Click here for file

[http://www.biomedcentral.com/content/supplementary/14712393-9-14-S1.pdf]

\section{Acknowledgements}

Vera Ehrenstein was supported by Ruth-Kirschstein NRSA Individual Predoctoral Fellowship from the National Institute of Neurological Disorders and Stroke (Grant No. F3I-NS05 I 994). Additional support was provided by the Western Danish Research Forum for Health Sciences and by the Clinical Epidemiologic Research Foundation. The funding sources played no role in the study design, data analysis, interpretation of results or any other aspect of this study.

\section{References}

I. Apgar V: A proposal for a new method of evaluation of the newborn infant. Curr Res Anesth Analg 1953, 32:260-267.
2. Casey BM, Mclntire DD, Leveno $\mathrm{KJ}$ : The continuing value of the Apgar score for the assessment of newborn infants. N Engl J Med 200I, 344(7):467-47I.

3. Badawi N, Kurinczuk J], Keogh JM, Alessandri LM, O'Sullivan F, Burton PR, Pemberton PJ, Stanley FJ: Antepartum risk factors for newborn encephalopathy: the Western Australian case-control study. BM] 1998, 3 I 7(7 I 72): 1549-1553.

4. Hagberg H, Wennerholm UB, Savman K: Sequelae of chorioamnionitis. Curr Opin Infect Dis 2002, I5(3):30I-306.

5. Cowan F, Rutherford M, Groenendaal F, Eken P, Mercuri E, Bydder GM, Meiners LC, Dubowitz LM, de Vries LS: Origin and timing of brain lesions in term infants with neonatal encephalopathy. Lancet 2003, 36 I (9359):736-742.

6. ACOG Committee Opinion. Number 333, May 2006 (replaces No. 174, July 1996): The Apgar score. Obstet Gynecol 2006, 107(5): |209-I2I2.

7. Apgar V: The newborn (Apgar) scoring system. Reflections and advice. Pediatr Clin North Am 1966, I3(3):645-650.

8. Thorngren-Jerneck K, Herbst A: Low 5-minute Apgar score: a population-based register study of I million term births. Obstet Gynecol 200I, 98(I):65-70.

9. Sorensen HT, Sabroe S, Olsen J, Rothman KJ, Gillman MW, Fischer P: Birth weight and cognitive function in young adult life: historical cohort study. BMJ 1997, 3 I 5(7 I 05):40|-403.

10. Sorensen HT, Steffensen FH, Olsen J, Sabroe S, Gillman M, Fischer P, Rothman KJ: Long-term follow-up of cognitive outcome after breech presentation at birth. Epidemiology 1999, 10:554-556.

II. Sorensen HT, Steffensen FH, Rothman KJ, Gillman MW, Fischer P, Sabroe S, Olsen J: Effect of home and hospital delivery on longterm cognitive function. Epidemiology 2000, I I (6):706-708.

12. Bergvall N, lliadou A, Johansson S, Tuvemo T, Cnattingius S: Risks for low intellectual performance related to being born small for gestational age are modified by gestational age. Pediatrics 2006, I I 7(3):e460-467.

13. Petterson B, Bourke J, Leonard H, Jacoby P, Bower C: Co-occurrence of birth defects and intellectual disability. Paediatr Perinat Epidemiol 2007, 2I(I):65-75.

14. Nelson $\mathrm{KB}$, Ellenberg $\mathrm{JH}$ : Obstetric complications as risk factors for cerebral palsy or seizure disorders. JAMA 1984, 25 I(I4): I843-I848.

15. Moster D, Lie RT, Irgens LM, Bjerkedal T, Markestad T: The association of Apgar score with subsequent death and cerebral palsy: A population-based study in term infants. J Pediatr 200I, 138(6): 798-803.

16. Sun Y, Vestergaard M, Pedersen CB, Christensen J, Olsen J: Apgar scores and long-term risk of epilepsy. Epidemiology 2006, I7(3):296-30।.

17. Ehrenstein V, Sørensen HT, Pedersen L, Larsen H, Holsteen V, Rothman KJ: Apgar score and hospitalization for epilepsy in childhood: a registry-based cohort study. BMC Public Health 2006, 6(1):23.

18. Moster D, Lie RT, Markestad T: Joint association of Apgar scores and early neonatal symptoms with minor disabilities at school age. Arch Dis Child Fetal Neonatal Ed 2002, 86(I):FI6-2I.

19. Krebs L, Langhoff-Roos J, Thorngren-Jerneck K: Long-term outcome in term breech infants with low Apgar score - a population-based follow-up. Eur J Obstet Gynecol Reprod Biol 200I, I00(I):5-8.

20. Odd DE, Rasmussen F, Gunnell D, Lewis G, Whitelaw A: A cohort study of low Apgar scores and cognitive outcomes. Arch Dis Child Fetal Neonatal Ed 2008, 93(2): FI I5-I20.

21. Seidman DS, Paz I, Laor A, Gale R, Stevenson DK, Danon YL: Apgar scores and cognitive performance at 17 years of age. Obstet Gynecol 1991, 77(6):875-878.

22. Nielsen GL, Dethlefsen C, Sorensen HT, Pedersen JF, Molsted-Pedersen $\mathrm{L}$ : Cognitive function and army rejection rate in young adult male offspring of women with diabetes: a Danish population-based cohort study. Diabetes Care 2007, 30(I I):2827-283I.

23. Baron JA, Weiderpass $E:$ An introduction to epidemiological research with medical databases. Ann Epidemiol 2000, I0(4):200-204.

24. Pedersen CB, Gotzsche H, Moller JO, Mortensen PB: The Danish Civil Registration System. A cohort of eight million persons. Dan Med Bull 2006, 53(4):44I-449. 
25. Knudsen LB, Olsen J: The Danish Medical Birth Registry. Dan Med Bull 1998, 45(3):320-323.

26. Mortensen EL, Reinisch JM, Teasdale. TW: Intelligence as measured by the WAIS and a military draft board test. Scand J Psychol 1989, 30:315-318.

27. Wechsler D: The measurement and appraisal of adult intelligence. 4th edition. Baltimore: Williams \& Wilkins; 1958.

28. Mortensen EL, Sorensen HJ, Jensen HH, Reinisch JM, Mednick SA: IQ and mental disorder in young men. Br J Psychiatry 2005, 187:407-4I5.

29. Zou G: A modified Poisson regression approach to prospective studies with binary data. Am J Epidemiol 2004, I 59(7):702-706

30. Allison PD: Missing Data. lowa City, IA: Sage Publications; 2002.

31. SAS Inc: SAS Documentation. [http://support.sas.com/documen tation/cdl/en/statug/59654/HTML/default/statug mi sect00l.htm].

32. Christensen J, Vestergaard M, Olsen J, Sidenius P: Validation of epilepsy diagnoses in the Danish National Hospital Register. Epilepsy Res 2007, 75(2-3): 162-170.

33. Lawlor DA, Najman JM, Batty GD, O'Callaghan MJ, Williams GM, Bor W: Early life predictors of childhood intelligence: findings from the Mater-University study of pregnancy and its outcomes. Paediatr Perinat Epidemiol 2006, 20(2): |48-162.

34. Rose G: Sick individuals and sick populations. Int J Epidemiol 1985, I 4(I):32-38.

35. Friborg J, Koch A, Stenz F, Wohlfahrt J, Melbye M: A PopulationBased Registry Study of Infant Mortality in the Arctic: Greenland and Denmark, 1973-1997. Am J Public Health 2004 94(3):452-457.

36. Brodie MJ, French JA: Management of epilepsy in adolescents and adults. Lancet 2000, 356(9226):323-329.

\section{Pre-publication history}

The pre-publication history for this paper can be accessed here:

http://www.biomedcentral.com/1471-2393/9/14/prepub
Publish with BioMed Central and every scientist can read your work free of charge

"BioMed Central will be the most significant development for disseminating the results of biomedical research in our lifetime. "

Sir Paul Nurse, Cancer Research UK

Your research papers will be:

- available free of charge to the entire biomedical community

- peer reviewed and published immediately upon acceptance

- cited in PubMed and archived on PubMed Central

- yours - you keep the copyright 